\title{
Catch-up growth in children with late-diagnosed coeliac disease
}

\author{
A. K. Patwari ${ }^{1}$, Gaurav Kapur ${ }^{1}$, L. Satyanarayana ${ }^{2}$, V. K. Anand ${ }^{1}$, Amit Jain ${ }^{1}$, Ashutosh Gangil ${ }^{1}$ \\ and Bharat Balani ${ }^{1}$ \\ ${ }^{1}$ Division of Pediatric Gastroenterology and Nutrition, Department of Pediatrics, Lady Hardinge Medical College \& Associated Kalawati \\ Saran Children's Hospital, New Delhi, India \\ ${ }^{2}$ Division of Epidemiology and Biostatistics, Institute of Cytology and Preventive Oncology (ICMR), NOIDA (UP), India
}

(Received 4 May 2004 - Revised 25 February 2005 - Accepted 1 March 2005)

\begin{abstract}
Anthropometric parameters and catch-up growth were prospectively evaluated in fifty late-diagnosed children with coeliac disease aged $2 \cdot 25-10$ years after $1-4$ years of adhering to a strict gluten-free diet (GFD). The anthropometric parameters were expressed as $Z$ scores relative to National Centre for Health Statistics standards using Epi Info 2000 (weight-for-height $Z$ score (WHZ) and height-for-age $Z$ score (HAZ)). Catch-up growth was evaluated by repeated measures. ANOVA, overall significance by an $F$ test and pair-wise comparisons for estimated marginal means using the least significant difference. At the time of enrolment, no significant difference was observed in WHZ and HAZ between children diagnosed before (group 1) or after (group 2) 4 years of age. On follow-up, HAZ was significantly higher in group 1 after the first and third years of the GFD $(P=0 \cdot 04$ and $0 \cdot 02$, respectively), with a non-significant increase after completing 4 years of the GFD $(P=0 \cdot 22)$. Feeding the GFD resulted in an overall significant $(F=3 \cdot 99, P=0 \cdot 011)$ increase in HAZ up to 4 years of follow-up. However, the catch-up in height was incomplete, with stunting in sixteen (55.4\%) of twenty-nine children after 3 years and in seven (46.6\%) of fifteen children after 4 years on the GFD. Pair-wise comparisons demonstrated a linear catch-up growth during the initial follow-up on GFD. Treatment with the GFD did not result in an overall significant increase in WHZ up to 4 years of follow-up $(F=1 \cdot 01, P=0.42)$. Our results suggest that, in children with late-diagnosed coeliac disease, treatment with a GFD leads to a normalisation of body mass and a significant but incomplete recovery in HAZ during 4 years of follow-up.
\end{abstract}

Catch-up growth: Gluten-free diet: Gluten enteropathy: Coeliac disease

Coeliac disease $(\mathrm{CD})$ is increasingly being diagnosed as an important cause of malabsorption in Indian children (Kumar et al. 1993; Yaccha et al. 1993; Patwari et al. 2003). Classically, CD presents at between 9 and 10 months of age (Walker Smith, 1985), but studies have now emphasised the changing pattern of presentation of CD over recent years (Maki et al. 1988). Cases of late-diagnosed monosymptomatic $\mathrm{CD}$ presenting with short stature as the only manifestation have been more frequently reported (Grikk et al. 1980; Rosenback et al. 1986). Most of the Indian studies have also reported a delayed diagnosis of CD (Kumar et al. 1993; Poddar, 1999; Patwari et al. 2003), which could be due to delayed weaning, a late introduction of gluten, delayed referral and lack of awareness about the disease. When CD is diagnosed early, the introduction of a gluten-free diet (GFD) promotes an accelerated growth rate (Rea et al. 1996), and normal height is reached in 12 months (Cataldo et al. 1987) to 2 years (Barr et al. 1972). The real duration of catch-up growth in the late-diagnosed $\mathrm{CD}$ patients is, however, not well defined (Bosio et al. 1990).

The exclusion of gluten from the diet modifies dietary composition, exposing children with $\mathrm{CD}$ to nutritional imbalance. This imbalance may be compounded in developing countries such as India as a result of poor access to nutritionally suitable alternatives for wheat. There is a paucity of data on the effects of a GFD on growth in children with $\mathrm{CD}$ in India. The present study aimed to assess catch-up growth in children with a delayed diagnosis of CD.

\section{Materials and methods}

Children of either sex diagnosed as having CD based on the modified European Society of Pediatric Gastroenterology and Nutrition criteria (Working Group of the European Society of Pediatric Gastroenterology and Nutrition, 1990) were prospectively studied. Diagnosis was also supported by a positive serology for CD (antigliadin antibody $\operatorname{IgG}$ and $\operatorname{IgA}$, anti-endomysial antibody $\operatorname{IgA}$ ). Children diagnosed with CD were started on a GFD and followed up in the Paediatric Gastroenterology and Nutrition Clinic. Children were encouraged to attend this clinic every month for the first 6 months, every 2 months over the following 6 months, quarterly for the next year and every 6 months thereafter. On regular follow-up, the children were assessed for details of diet (to ascertain compliance and quality of food intake), symptomatic improvement and anthropometric assessment. Children with irregular follow-up who had taken the GFD for less than 6 months or with doubtful compliance were excluded from the final analysis.

\section{Anthropometric assessment}

Body weight was determined by subjects standing bare foot in light clothing on a digital scale. While recording the weight, shoes, long trousers, sweaters and other heavy clothing were removed. Weight was recorded to the nearest $100 \mathrm{~g}$. Height 
without shoes was measured with a wall-mounted stadiometer graded in centimeters with the head in the Frankfurt plane. The height was recorded to the nearest $0 \cdot 1 \mathrm{~cm}$.

Socioeconomic status was assessed by:

- monthly family income;

- the educational status of the parents, graded according to a previously described score (Kappu Swamy, 1976), the sum of the graded educational scores of the father and mother being used for statistical analysis;

- the total number of dependents;

- the birth order of the child.

The official Wholesale Price Index for all the commodities during the corresponding years was taken into consideration to adjust for income the categories outlined in the score.

\section{Gluten-free diet}

In northern India, wheat is the staple diet and is taken in the form of 'chapati' (Indian bread made of unleavened wheat dough prepared on a griddle). As gluten-free wheat is not available in our hospital or in the open market, the GFD consisted of 'chapati' made of soyabean-rice flour $(1: 3 \mathrm{w} / \mathrm{w}$ protein $15 \mathrm{~g}$, energy $366 \mathrm{~kJ}$ per $100 \mathrm{~g})$, rice-bengal gram flour $(1: 1 \mathrm{w} / \mathrm{w}$ protein $11.9 \mathrm{~g}$, energy $352 \mathrm{~kJ}$ per $100 \mathrm{~g})$ or maize-soyabean flour $(3: 1 \mathrm{w} / \mathrm{w}$ protein $19.1 \mathrm{~g}$, energy $364 \mathrm{~kJ}$ per $100 \mathrm{~g}$ ). During hospitalisation, the GFD was prepared in the hospital kitchen and distributed free of cost. The families were shown how to make 'wheat-free chapatis' in the hospital, and after discharge from the hospital the GFD was prepared and served by the families themselves. In view of a potential risk of adulteration with wheat particles while milling the non-wheat cereals, the families were specifically counselled to mill the rice, soyabean, maize or bengal gram in special mills or in a domestic mixer.

Compliance with the GFD was ensured by a thorough counselling of all the family members (school teachers as well when requested by the parents or deemed necessary by the investigators), and accidental ingestion was prevented by forbidding foodstuffs known to contain gluten and checking the composition and commercial labels of all unknown food items, including toffees, chocolates, ice creams, juices, etc. All the children received Fe and folic acid supplementation.

\section{Statistical analysis}

For statistical comparison, height-for-age and weight-for-height were expressed as $Z$ scores (HAZ and WHZ, respectively) relative to National Centre for Health Statistics standards (Hamill et al. 1979) using the computer software package Epi Info 2000. The maximum height and age limitations for WHZ calculation (age: boys 11.5 years, girls 9 years; maximum height: boys $145.0 \mathrm{~cm}$, girls $137 \mathrm{~cm}$ ) were taken into consideration, and these cases were excluded from statistical analysis (Gorstein et al. 1994). Cut-off points for defining malnutrition as the $Z$ score from the reference median included HAZ -2 to -3 (moderate stunting) and $<-3$ (severe stunting), and WHZ -2 to -3 (moderate wasting) and $<-3$ (severe wasting) (Cartson \& Wardlaw, 1990).

Evaluation of catch-up growth for up to 4 completed years based on WHZ and HAZ for between-subject factors such as age and sex was performed while adjusting for the educational scores of parents, family income, the number of dependents and the birth order using repeated-measures ANOVA. SPSS statistical software version 10.0 (SPSS Inc., Chicago, IL, USA) was used for the analysis. The overall significance of catch-up growth using WHZ and HAZ was evaluated by the $F$ test. The pair-wise comparisons for estimated marginal means at different completed years of follow-up were made using least significant difference. A value of $P<0 \cdot 05$ was taken as significant.

\section{Results}

\section{General characteristics}

Sixty children (thirty-eight girls and twenty-two boys) aged 2.2512 years of age (mean 7.6 (SD 2.37) years) entered the study and were started on a GFD. The children enrolled came from urban areas around Delhi as well as rural and semi-urban and rural areas of the neighbouring states. These children belonged to upper middle and lower middle as well as poor socio-economic classes. The duration of their symptoms prior to diagnosis ranged from 3 months to 10 years (mean 5.8 (SD 2.6) years). Stunted growth $(100 \%)$, pallor $(100 \%)$ and diarrhoea $(91.6 \%)$ were the predominant clinical features at the time of diagnosis of CD. Fifty children ( $83 \%$; thirty-three girls and seventeen boys) aged $2 \cdot 25-10$ years at diagnosis (mean 5.46 (SD 2.3) years) who regularly attended for follow-up and showed strict dietary compliance were included in the assessment of catch-up growth after the GFD had been instituted. Therefore, at the time of assessment of catch-up growth, fifty children $(100 \%)$ had completed 1 year, forty $(80 \%) 2$ years, twenty-nine $(58 \%) 3$ years and fifteen $(30 \%) 4$ years of the GFD.

Age at diagnosis. The effect of a delayed diagnosis of $\mathrm{CD}$ on nutritional indicators was studied by dividing the study group into two age groups. The study group comprised children who had been diagnosed between 2 and 4 years of age (group 1) and those diagnosed after the age of 4 years (group 2). At the time of diagnosis of $\mathrm{CD}$, the mean WHZ and HAZ of the children in group 1 ( $n$ 19) were relatively higher than those of group 2

Table 1. Age of diagnosis of coeliac disease and nutritional indicators $†$ after $1,2,3$ and 4 years of a gluten-free diet (GFD)

\begin{tabular}{|c|c|c|c|c|c|}
\hline & \multicolumn{2}{|c|}{$\begin{array}{l}\text { Group } 1 \\
\text { (2-4 years) }\end{array}$} & \multicolumn{2}{|c|}{$\begin{array}{l}\text { Group } 2 \\
(>4 \text { years })\end{array}$} & \multirow[b]{2}{*}{$P$ value } \\
\hline & Mean & SD & Mean & SD & \\
\hline At the time of diagnosis & \multicolumn{2}{|c|}{$n 19$} & \multicolumn{2}{|c|}{$n 31$} & \\
\hline WHZ S & -1.08 & 1.20 & -1.34 & 1.33 & 0.48 \\
\hline HAZ S & $-3 \cdot 10$ & 1.29 & $-3 \cdot 85$ & 1.59 & 0.07 \\
\hline Completed 1 year on GFD & \multicolumn{2}{|c|}{$n 19$} & \multicolumn{2}{|c|}{$n 31$} & \\
\hline WHZ 1 & 0.43 & 0.92 & 0.68 & 1.04 & 0.39 \\
\hline HAZ 1 & $-2 \cdot 29$ & 1.25 & -3.09 & 1.35 & $0.04^{*}$ \\
\hline Completed 2 years on GFD & \multicolumn{2}{|c|}{$n 15$} & \multicolumn{2}{|c|}{$n 25$} & \\
\hline WHZ 2 & 1.00 & $1 \cdot 38$ & 0.4 & 1.45 & 0.27 \\
\hline HAZ 2 & -1.95 & $1 \cdot 2$ & -2.89 & $1 \cdot 7$ & 0.05 \\
\hline Completed 3 years on GFD & \multicolumn{2}{|c|}{$n 10$} & \multicolumn{2}{|c|}{$n 19$} & \\
\hline WHZ 3 & 0.85 & 1.04 & $0 \cdot 18$ & 1.01 & 0.13 \\
\hline HAZ 3 & -1.5 & $1 \cdot 18$ & $-2 \cdot 64$ & 1.27 & $0.02^{*}$ \\
\hline Completed 4 years on GFD & \multicolumn{2}{|c|}{$n 10$} & \multicolumn{2}{|c|}{$n 19$} & \\
\hline WHZ 4 & 0.89 & $1 \cdot 16$ & 0.79 & 0.4 & 0.84 \\
\hline HAZ 4 & -1.64 & 0.56 & $-2 \cdot 13$ & 0.92 & 0.22 \\
\hline
\end{tabular}

* Mean values were significantly different, ${ }^{*} P<0.05$.

†WHZ S, WHZ 1, WHZ 2, WHZ 3, WHZ 4: weight-for-height $Z$ score at the start of the GFD and after $1,2,3$ and 4 years of the GFD, respectively. HAZ S, HAZ 1, HAZ 2, HAZ 3, HAZ 4: equivalent height-for-age $Z$ scores. 
Table 2. Pair-wise comparison of weight-for-height and height-for-age $Z$ scores after $1,2,3$ and 4 years on a gluten-free diet (GFD)

\begin{tabular}{|c|c|c|c|c|c|}
\hline Measure & $\begin{array}{l}\text { Year of completion } \\
\text { of GFD (I)§ }\end{array}$ & $\begin{array}{l}\text { Year of completion } \\
\text { of GFD (J)\| }\end{array}$ & Mean difference $(I-J)$ & SE & Significance \\
\hline \multirow[t]{20}{*}{ Weight-for-height $Z$ score } & 1 & 2 & $-1 \cdot 714^{\star}$ & 0.319 & 0.000 \\
\hline & & 3 & $-1.975^{\star}$ & 0.350 & 0.000 \\
\hline & & 4 & $-1 \cdot 702^{*}$ & 0.289 & 0.000 \\
\hline & & 5 & $-2 \cdot 146^{\star}$ & 0.333 & 0.000 \\
\hline & 2 & 1 & $1 \cdot 714^{*}$ & 0.319 & 0.000 \\
\hline & & 3 & -0.261 & 0.195 & 0.193 \\
\hline & & 4 & 1.167E-02 & 0.249 & 0.963 \\
\hline & & 5 & 0.213 & 0.332 & 0.533 \\
\hline & 3 & 1 & $1.975^{*}$ & 0.350 & 0.000 \\
\hline & & 2 & 0.261 & 0.195 & 0.193 \\
\hline & & 4 & 0.273 & 0.195 & 0.176 \\
\hline & & 5 & 0.597 & 0.326 & 0.095 \\
\hline & 4 & 1 & $1 \cdot 702^{*}$ & 0.289 & 0.000 \\
\hline & & 2 & $-1 \cdot 167 \mathrm{E}-02$ & 0.249 & 0.963 \\
\hline & & 3 & -0.273 & 0.195 & 0.176 \\
\hline & & 5 & $-4.500 \mathrm{E}-02$ & 0.251 & 0.861 \\
\hline & 5 & 1 & $2 \cdot 146^{\star}$ & 0.333 & 0.000 \\
\hline & & 2 & -0.213 & 0.332 & 0.533 \\
\hline & & 3 & -0.597 & 0.326 & 0.095 \\
\hline & & 4 & $4.500 \mathrm{E}-02$ & 0.251 & 0.861 \\
\hline \multirow[t]{20}{*}{ Height-for-age $Z$ score } & 1 & 2 & $-0.710^{\star}$ & 0.175 & 0.000 \\
\hline & & 3 & $-1 \cdot 114^{*}$ & 0.232 & 0.000 \\
\hline & & 4 & $-1 \cdot 735^{\star}$ & 0.183 & 0.000 \\
\hline & & 5 & $-1.676^{*}$ & 0.284 & 0.000 \\
\hline & 2 & 1 & $0.710^{*}$ & 0.175 & 0.000 \\
\hline & & 3 & $-0.404^{*}$ & 0.170 & 0.26 \\
\hline & & 4 & $-1.025^{\star}$ & 0.174 & 0.000 \\
\hline & & 5 & $-1 \cdot 260^{*}$ & 0.273 & 0.001 \\
\hline & 3 & 1 & $1 \cdot 114^{*}$ & 0.232 & 0.000 \\
\hline & & 2 & $0.404^{*}$ & 0.170 & 0.026 \\
\hline & & 4 & $-0.622^{*}$ & 0.155 & 0.001 \\
\hline & & 5 & $-0.743^{\star}$ & 0.211 & 0.005 \\
\hline & 4 & 1 & $1 \cdot 735^{*}$ & 0.183 & 0.000 \\
\hline & & 2 & $1.025^{*}$ & 0.174 & 0.000 \\
\hline & & 3 & $0.622^{*}$ & 0.155 & 0.001 \\
\hline & & 5 & 5.000E-02 & 0.099 & 0.624 \\
\hline & 5 & 1 & $1 \cdot 676^{\star}$ & 0.284 & 0.000 \\
\hline & & 2 & $1 \cdot 260^{*}$ & 0.273 & 0.001 \\
\hline & & 3 & $0.743^{*}$ & 0.211 & 0.005 \\
\hline & & 4 & $-5 \cdot 000 \mathrm{E}-02$ & 0.099 & 0.624 \\
\hline
\end{tabular}

${ }^{*}$ Mean values were significantly different, ${ }^{*} P<0.05$

$\ddagger$ Adjustment for multiple comparisons: least significant difference (equivalent to no adjustments).

$\S 1$, on enrolment; 2 , after 1 year of GFD; 3 , after 2 years of GFD; 4 , after 3 years of GFD; 5 , after 4 years of GFD.

|| 1 , on enrolment; 2, after 1 year of GFD; 3 , after 2 years of GFD; 4 , after 3 years of GFD; 5 , after 4 years of GFD.

(n 31; Table 1), but the differences were statistically insignificant $(P=0.48$ and 0.07 , respectively).

Overall catch-up growth and pair-wise comparisons. Table 2 shows the pair-wise effective mean differences of WHZ and HAZ and their significance between different years of completion of the GFD obtained from repeated-measures ANOVA.

In terms of height-for-age, twenty-nine $(58 \%)$ of the fifty children at diagnosis had an HAZ $<-3$ SD, twelve $(24 \%)$ had a score of -2 to $-3 \mathrm{SD}$, and nine $(18 \%)$ had an HAZ of between -2 and 0 (Fig. 1). The mean and standard deviation for the HAZ at the time of enrolment were -3.58 (SD 1.56). Feeding the GFD resulted in an overall significant $(F=3.99, \quad P=0.011)$ increase in HAZ for up to 4 years of follow-up (Figs. 2 and 3). On pair-wise comparison, the HAZ showed a significant increase at each year of completion of the GFD compared with the previous year except between the third and fourth years of completion. The catch-up in height was incomplete as sixteen $(55.4 \%)$ of the twenty-nine children who had completed 3 years and seven $(46.6 \%)$ of the fifteen who had completed 4 years of the GFD remained stunted.

With regard to weight-for-height, thirteen $(26 \%)$ of fifty children were wasted at diagnosis, with three (30\%) severely wasted and ten $(70 \%)$ moderately wasted children. The mean WHZ score at the time of enrolment was -1.19 (SD 1.28). Treatment with the GFD did not result in an overall significant increase in WHZ up to 4 years of follow-up $(F=1 \cdot 01, P=0 \cdot 42)$. The pairwise comparisons in the case of WHZ indicate that the scores of children on enrolment were significantly lower than the subsequent scores. However, none of the mean differences of other pairs at later follow-ups was significant. None of the patients showed wasting at the end of the first year on the GFD. There was an overshoot in WHZ after completing the fourth year of GFD, but this was not statistically significant. 


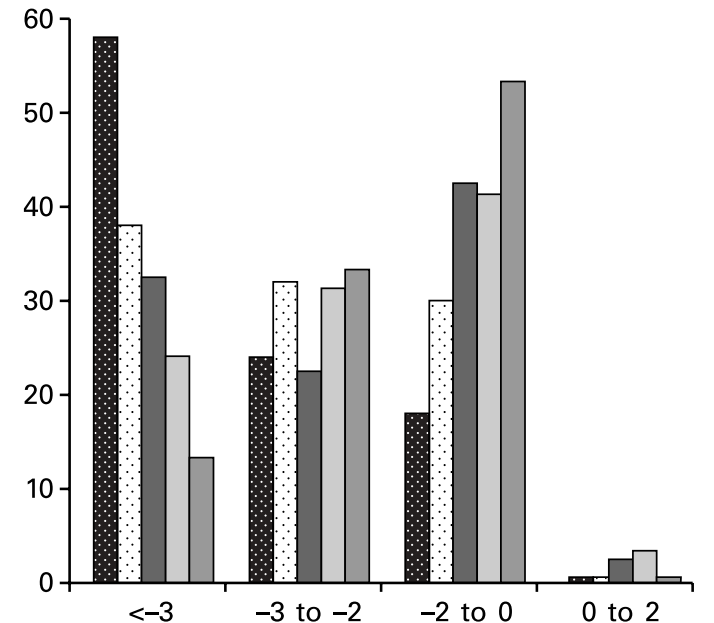

Fig. 1. Distribution of height-for-age $Z$ scores at diagnosis (HAZ S) and during follow-up at 1 (HAZ 1), 2 (HAZ 2), 3 (HAZ 3) and 4 (HAZ 4) years on a gluten-free diet. Haz S ( $n$ 50); $\square \mathrm{Haz} 1$ ( $n$ 50); $\square \mathrm{Haz} 2$ ( $n$ 40); $\square \mathrm{Haz} 3$ (n 29); $\square \operatorname{Haz} 4$ (n 15)

\section{Influences on catch-up growth}

Age at diagnosis. The effect of a delayed diagnosis of $\mathrm{CD}$ on catch-up growth was studied by comparing the results of group 1 (children diagnosed between 2 and 4 years of age) and group 2 (diagnosed after the age of 4 years). There was no significant difference in WHZ in terms of the catch-up growth between the two age groups on follow-up $(P=0.89,0.47,0.533$ and 0.35 at the completion of $1,2,3$ and 4 years of the GFD, respectively). After completing the first and third years on the GFD, HAZ was significantly higher in group $1(P=0.04$ and 0.02 , respectively), but it was marginally higher $(P=0.05)$ after completing the second year. At the end of fourth year of the GFD, there was no significant difference in HAZ between the groups $(P=0.22$; Table 1$)$. However, six $(66.6 \%)$ of the nine children in group 2 but only one $(16.6 \%)$ of six children in group 1 remained stunted.

Sex. There were no significant differences between the boys ( $n$ 17) and girls ( $n$ 33) at all times when their anthropometric parameters were compared at the time of diagnosis and during follow-up.

Other covariates. There was a positive correlation between the educational status of the parents and HAZ on diagnosis of

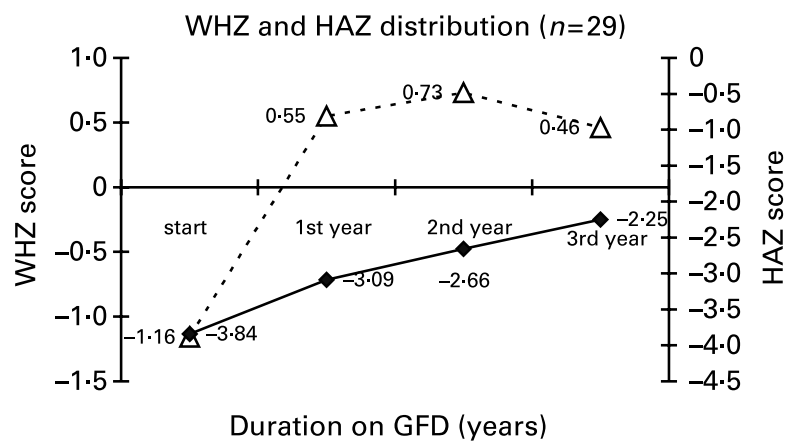

Fig. 2. Weight-for-height (WHZ; $\triangle$ ) and height-for-age (HAZ; $\bullet$ ) score distribution for twenty-nine children after 3 years on a gluten-free diet (GFD).
WHZ and HAZ distribution $(n=15)$

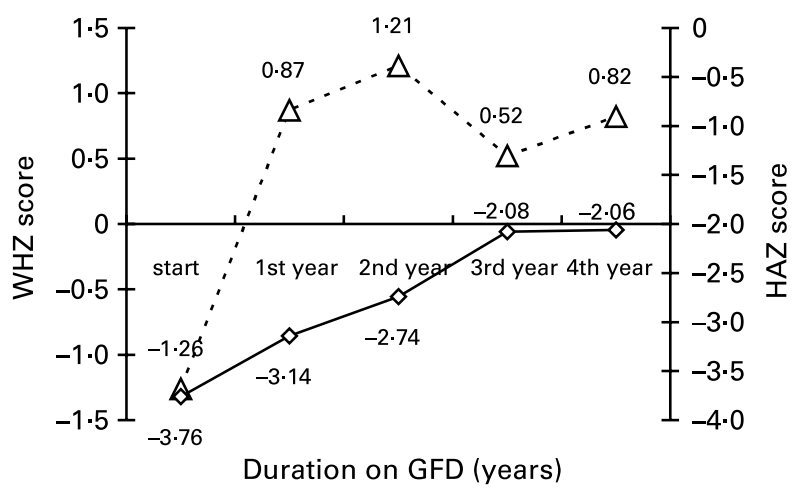

Fig. 3. Weight-for-height (WHZ; $\triangle$ ) and height-for-age (HAZ; $\diamond$ ) score distribution for fifteen children after 4 years on a gluten-free diet (GFD).

CD $(P=0 \cdot 35)$ and on follow-up on the GFD until the end of the first year $(P=0.046)$. However, after the completion of the second year of GFD and thereafter, no correlation was observed between educational status and HAZ. There were one or two dependents in forty-one $(82 \%)$ of these families, and the child's birth order was one or two in forty-eight $(96 \%)$ instances. The number of dependants in the family correlated directly with the age at which $\mathrm{CD}$ had been diagnosed.

The interquartile range Rs 3500/- was taken as the cut-off point for family income. The mean WHZ at the start of GFD and at other follow-ups in the lower and higher income categories was not significant. However, the initial HAZ $(P<0 \cdot 001)$ in these categories ( -4.56 (SD 1.53) and -2.96 (SD 1.16)) and at first followup $(P<0.001)$ in the lower and higher income categories $(-3.68$ (SD 1.45) and -2.24 (SD 0.98)) was statistically significant. The differences were not significant at follow-up from the second to the fourth year.

\section{Discussion}

The control of the growth process is related to many complex interacting factors, including biological characteristics such as genotype, external factors such as nutrition and environment, and internal signalling systems such as hormones and growth factors. Catch-up growth, a discontinuous process made up of a sequence of bursts of growth followed by a resting phase (Greco et al. 1994), is defined as rapid, compensatory growth during rehabilitation from prior nutritional deficit or illness (World Health Organization, 1995). During catch-up, the child may grow in height at up to four times the average rate for his or her chronological age. As the child approaches his or her genetically predisposed channel, the restoring force diminishes and the growth velocity again decreases (Prader et al. 1963; Tanner, 1981).

The nutritional rehabilitation of CD patients with a GFD leads to an acceleration in growth (Prader et al. 1963; Barr et al. 1972; Cataldo et al. 1987; Luca et al. 1988; Bosio et al. 1990; Hernandez et al. 1992; Damen et al. 1994). The present study also revealed an accelerated growth, manifested as a significant improvement in HAZ and WHZ, when a GFD was instituted. After the start of therapy, weight-forheight normalised at the end of first year of the GFD (WHZ 
$>-2 \mathrm{SD})$ and overshot during the second year of the GFD. This pattern, as reported in earlier studies (Barr et al. 1972; Greco et al. 1994), indicates that weight catches up more quickly than height, leading to a transitory status of overweight. The increase in WHZ at the end of the fourth year of the GFD could be attributed to continued weight gain. Pair-wise catch-up growth comparisons clearly demonstrated that the WHZ of children on enrolment was significantly lower than subsequent scores, but none of the mean differences of other pairs at later follow-ups was significant. HAZ, on the other hand, demonstrated a significant increase at each year of completion of the GFD compared with the previous year, except between the third and fourth years of completion of the GFD. The present results therefore suggest that there is a linear catch-up growth in terms of height during the initial follow-up on a GFD.

Barr et al. (1972) and others (Luca et al. 1988; Bosio et al. 1990; Hernandez et al. 1992; Damen et al. 1994; World Health Organization, 1995; Gerolamo et al. 1999) have reported a variability in the growth pattern of patients with CD: both a complete (Barr et al. 1972; Bosio et al. 1990; Hernandez et al. 1992; Damen et al. 1994; Greco et al. 1994) and an incomplete (Cataldo et al. 1987; Luca et al. 1988; Gerolamo et al. 1999) catch-up in height when $\mathrm{CD}$ is diagnosed at an early stage (less than 2 years, Barr et al. 1972; Damen et al. 1994; World Health Organization, 1995; Gerolamo et al. 1999) and with late diagnosis (Luca et al. 1988; Bosio et al. 1990; Damen et al. 1994). The present study reveals a persistence of stunting even after 4 years of the GFD; this could be due to the following:

- catch-up in height in severely stunted children takes a relatively longer time even with a favourable environment (World Health Organization, 1986);

- late-diagnosed patients show a slower and seemingly incomplete catch-up growth (Bosio et al. 1990);

- multiple alterations occur in the growth axis (growth hormone-binding proteins, insulin-like growth factor-1, insulinlike growth factor binding protein) during the active phase of the disease (Federico et al. 1997);

- negative effects of CD on growth (Gerolamo et al. 1999).

In the present study, children with an early diagnosis demonstrated better increments in height than children diagnosed late. This is shown by: a lower severity of stunting at diagnosis, although statistically insignificant; a higher HAZ on follow-up of 4 years; the prevalence of stunting at the end of the fourth year on the GFD (six of nine children in group $2 v$. only one of six children in group 1). Studies have reported a complete catch-up in height (Hernandez et al. 1992; Damen et al. 1994; Luciano et al. 2002) if CD is diagnosed prior to 9 years of age, although patients diagnosed after the age of 2 years tend to maintain a body size slightly below the mean (Hernandez et al. 1992).

The correlation at diagnosis and HAZ as follow-up for 3 years could be due to the influence of environmental factors in the initial phase of catch-up growth. No correlation was observed with WHZ, which could be because of the obvious biological differences between wasting and stunting. Wasting is precipitated by infection and usually occurs in situations where food supply is limited. Stunting is frequently associated with poor overall economic conditions, especially mild-to-moderate, chronic or repeated infection, as well as inadequate nutrient intake (World Health Organization, 1986).
Studies have reported that the rate of catch-up growth would be higher if the initial statural deficit were more pronounced (Damen et al. 1994). In the present study as well, there was a positive correlation between HAZ on diagnosis of CD and HAZ on follow-up while receiving the GFD. HAZ at diagnosis correlated positively with educational status and family income at diagnosis and at the initial follow-up after the first year of the GFD, but the differences were statistically insignificant at other follow-ups.

In conclusion, the GFD leads to a normalisation of body mass (evaluated as weight-for-height) and a substantial improvement in height-for-age in developing countries such as India where children have minimal access to nutritionally suitable alternatives to wheat. Apart from the GFD, careful followup and good compliance with the dietary rules are mandatory for optimising children's growth potential. The present study highlights that there is a linear catch-up growth in terms of height during the initial follow-up on the GFD. The increments in height may be influenced by age at the time of diagnosis of $\mathrm{CD}$ and to some extent by the educational and economic status of the parents.

\section{References}

Barr DGD, Shomerling DH \& Prader A (1972) Catch-up growth in malnutrition, studied in celiac disease after institution of gluten free diet. Pediatr Res 6, 521-527.

Bosio L, Barera G, Mistura L, Sassi G \& Bianchi C (1990) Growth acceleration and final height after treatment for delayed diagnosis of celiac disease. J Pediatr Gastroenterol Nutr 11, 324-329.

Cartson BA \& Wardlaw TM (1990) A Global, Regional and Country Assessment of Child Malnutrition. UNICEF Staff Working Paper no. 7. New York: UN Children's Fund.

Cataldo F, La Tena D, Mirto G, La Monaca P \& Albeggiani A (1987) Compartmento dello stato auxologico edi almini indici nutrizonali in ungruppo di bambini celiaci. Minerva Pediatr 39, 187-190.

Damen GM, Boersma B, Wit JM \& Heymans HS (1994) Catch up growth in 60 children with celiac disease. J Pediatr Gastroenterol Nutr 19 394-400.

Federico G, Favilli T, Cinquanta L, Ughi C \& Saggese G (1997) Effect of celiac disease and gluten free diet on growth hormone binding protein, insulin-like growth factor-1, and insulin-like growth factor-binding protein. Horm Res 48, 108-114.

Gerolamo G, Vignolo M, Nuselli A \& Garzia P (1999) Linear growth and skeletal maturation in subjects with treated celiac disease. J Pediatr Gastroenterol Nutr 29, 339-342.

Gorstein J, Sullivan K, Yip R, de Onis M, Trowbridge F, Fajans P \& Clugston G (1994) Issues in the assessment of nutritional status using anthropometry. Bull World Health Organ 72, 273-283.

Greco L, Tipo V, Donato Di F \& Mayer M (1994) Pulsatile growth during catch up growth in childhood celiac disease. Acta Pediatr 83, 724-729.

Grikk A, Prece MA, Candy DCA \& Tanner JM (1980) Short stature as primary manifestation of celiac disease. Lancet ii, 1097-1099.

Hamill PVV, Drizd TA, Johnson CL, Reed RB, Roche AF \& Moore WM (1979) Physical growth: National Center for Health Statistics. Am J Clin Nutr 32, 607-629.

Hernandez M, Argente J, Navarro A, Caballo N, Barrios V, Hervas F \& Polanco (1992) Growth in malnutrition related to gastrointestinal diseases: celiac disease. Horm Res 38, Suppl 1, 79-84.

Kappu Swamy B (1976) Manual of Socio-economic Status Scale (Urban). Delhi: Manasayan.

Kumar M, Yaccha SK \& Naik SR (1993) Celiac disease in children. Indian J Gastroenterol 12, A15. 
Luca De F, Astori M, Panduelo E, Sferlazzas C, Arrigo T, Sindeni A \& Magazzu G (1988) Effect of gluten free diet on catch up growth and height prognosis in celiac children with growth retardation recognized after the age of 5 years. Eur J Pediatr 147, $188-191$

Luciano A, Bolognani M, Di Falco A, Trabucchi C, Bonetti P \& Castellar A (2002) Catch up growth and final height in celiac disease. Pediatr Med Chir 24, 9-12.

Maki M, Kallonen K, Lahdeaho ML \& Visakorpi JK (1988) Changing pattern of childhood celiac disease in Finland. Acta Paediatr Scand 77, 408-412.

Patwari AK, Anand VK, Kapur G \& Narayan S (2003) Clinical and nutritional profile of children with celiac disease. Indian Pediatr 40, $337-342$.

Poddar U (1999) Celiac disease: clinical features and diagnostic criteria. Indian J Pediatr 66, S21-S25.

Prader A, Tanner JM \& Von Harnach GA (1963) Catch up growth following illness or starvation. An example of developmental canalisation in man. J Pediatr 62, 646-659.

Rea F, Polito C, Marotta A, Di Toro A, Iovene A, Collini R, Rea L \& Sessa G (1996) Restoration of body composition in celiac children after one year of gluten-free diet. J Pediatr Gastroenterol Nutr 23, 408-412.

Rosenback Y, Dinari G, Zahavi I \& Nitzan M (1986) Short stature as the major manifestation of celiac disease in older children. Clin Pediatr 25, $13-16$.

Tanner JM (1981) Catch up growth in man. Br Med Bull 37, 233-238.

Walker Smith JA (1985) Celiac disease. In Diseases of Small Intestine in Children, 3rd ed. pp. 88-143 [JA Walker Smith, editor]. London: Butterworth-Heinemann.

Working Group of the European Society of Pediatric Gastroenterology and Nutrition (1990) Revised criteria for diagnosis of celiac disease. Arch Dis Child 65, 909-911.

World Health Organization (1995) Physical Status: The Use and Interpretation of Anthropometry. Report of a WHO Expert Committee. WHO Technical Report Series no. 854. Geneva: WHO.

World Health Organization Working Group (1986) Use and interpretation of anthropometric indicators of nutritional status. Bull World Health Organ 64, 929-941.

Yaccha SK, Misra S, Malik AK, Nagi B \& Mehta S (1993) Spectrum of malabsorption syndrome in North Indian children. Indian J Gastroenterol 12, 120-125. 